1 Instituto Federal de Educação Ciência e Tecnologia de Pernambuco (IFPE) - Pesqueira (PE), Brasil. valquiria@pesqueira.ifpe. edu.br

2 Universitat Rovira i Virgili (URV), Antropología y Comunicación - Cataluña, Espanha. Universidade Federal de Santa Catarina (UFSC) - Florianópolis (SC), Brasil.

martinhagofernanda@gmail.com

3 Secretaria Municipal de Saúde - Joinville, (SC), Brasil. angelahoepfner@hotmail.com

4 Universidade Federal de Santa Catarina (UFSC) Florianópolis (SC), Brasil. patriciakdare@gmail.com

5 Universidade Federal de Santa Catarina (UFSC) Florianópolis (SC), Brasil. sandracaponi@gmail.com

\section{O cuidado em saúde mental no Brasil: uma leitura a partir dos dispositivos de biopoder e biopolítica}

\author{
The mental health care in Brazil: a reading from the biopower and \\ biopolitics devices
}

Valquiria Farias Bezerra Barbosa1, Fernanda Martinhago ${ }^{2}$, Ângela Maria da Silva Hoepfner ${ }^{\mathbf{3}}$, Patrícia Kozuchovski Daré4, Sandra Noemi Cucurullo de Caponi ${ }^{\mathbf{5}}$

RESUMO O presente artigo objetiva problematizar o cuidado em saúde mental no Brasil à luz dos conceitos de biopoder e biopolítica, enunciados por Michel Foucault. A análise das práticas de cuidado instituídas no âmbito dos serviços que compõem a rede de atenção psicossocial no Brasil, através de artigos publicados em periódicos nacionais, revelou a transversalidade do cuidado em saúde mental com relação a estratégias disciplinares e de controle das populações, limitando as possibilidades de resgate da concepção de sujeito e subjetividade no processo de produção do cuidado às pessoas em sofrimento psíquico.

PALAVRAS-CHAVE Saúde mental; Padrão de cuidado; Desinstitucionalização.

\begin{abstract}
This article aims to problematize the mental health care in Brazil in the light of the concepts of biopower and biopolitics, announced by Michel Foucault. The analysis of care practices imposed in the scope of the services that compose the psychosocial care network in Brazil, through articles published in national journals, revealed the mainstreaming of mental health care regarding disciplinary and control populations strategies, limiting the possibilities of rescue of the subject and subjectivity conception in the process of care production to people in psychological suffering.
\end{abstract}

KEYWORDS Mental health; Standard of care; Deinstitucionalization. 


\section{Introdução}

A reorientação do modelo de atenção à saúde mental no Brasil proporcionou notáveis avanços na organização e na concepção dos serviços. No entanto, as resistências de superação do modelo biomédico, no âmbito dos processos de cuidado, mais especificamente, nos Centros de Atenção Psicossocial (Caps) têm sido amplamente debatidas.

Esse contexto exige dos profissionais de saúde, que desenvolvem sua atuação técnica e seu protagonismo social em serviços de saúde mental uma aguçada vigilância epistêmica, num constante processo de ação-reflexão-ação, no sentido de evitar a persistência do antigo modelo de poder psiquiátrico, pré-moderno e pré-capitalista, resíduo das práticas norteadas pelo poder soberano (CAPONI, 2012).

É nessa perspectiva que o presente artigo tem como objetivo tecer uma reflexão teórica sobre os aspectos limitantes dos processos de cuidado às pessoas em sofrimento psíquico no âmbito dos serviços de saúde mental brasileiros, à luz dos conceitos de biopoder e biopolítica enunciados por Michel Foucault. Inicialmente faz-se uma incursão sobre a história do hospital, para compreender de que forma os manicômios tornaram-se o dispositivo central de medicalização da loucura. Na sequência, problematizam-se as condições que possibilitam ou não a consolidação do modo de atenção psicossocial no Brasil, à luz do dispositivo de segurança e da biopolítica das populações, articulando os textos clássicos em que Michel Foucault discute biopolítica e poder psiquiátrico. São também apresentados alguns autores contemporâneos que recorrem ao autor para ampliar as discussões sobre diferentes aspectos relacionados ao cuidado em saúde mental.

\section{A institucionalização da loucura}

A institucionalização dos loucos teve início na idade média a partir de um movimento de exclusão social. A chamada 'Nau dos Loucos' é um exemplo dessa exclusão. Pessoas consideradas 'loucas' eram colocadas nos porões dos barcos e lançadas ao mar durante as travessias transoceânicas.

\section{A internação é uma criação institucional pró- pria ao século XVII. [...] Como medida eco- nômica e precaução social ela tem valor de invenção. (FOUCAULT, 2008A, P. 78).}

Os hospitais existentes desde a idade média, não eram voltados para a cura, e a prática médica não fazia parte das intervenções realizadas nestas instituições. Hospitais eram destinados apenas a acolher os desabrigados, pobres e doentes, como uma instituição de caridade que prestava assistência material e religiosa e que, por consequência, contribuía para evitar a disseminação das doenças, protegendo a população. O hospital era o lugar para se receber os últimos cuidados e o último sacramento, um morredouro. No entanto, as precárias condições de higiene e a inexistência de medidas de assepsia, fizeram dos hospitais foco constante de desordem, devido às doenças que se proliferavam em seu ambiente, assim como nas cidades (FOUCAULT, 2011).

Entre os séculos XVII e XVIII, o ocidente vivenciou a transição entre duas formas de poder: o poder soberano e o biopoder. Isso quer dizer que os fenômenos próprios da vida humana entraram na ordem do saber e do poder, no campo das técnicas políticas, assumindo duas formas imbricadas de poder: i) o adestramento dos corpos como máquinas, ampliando suas aptidões para a força de trabalho, extorquindo suas forças, acentuando sua utilidade e docilidade, pela integração em sistemas de controle eficazes e econômicos, assegurado por procedimentos de poder disciplinares; ii) a biopolítica das populações, admitindo-se uma série de intervenções e controles reguladores no corpo-espécie, no corpo transpassado pela 
mecânica do ser vivo e como suporte de processos biológicos (FOUCAULT, 1994).

Assim, na sociedade disciplinar, as instituições modernas - como a prisão, a escola, as fábricas e o hospital - passaram a ser o locus do adestramento dos corpos com vistas a potencializar suas forças e aumentar sua eficiência, sendo que, nesse contexto, mais precisamente em torno de 1780 , o hospital passou a ser uma espécie de instrumento terapêutico, propiciando o surgimento de uma nova proposta de trabalho: a prática da visita e da observação sistemática e comparada, com o objetivo de cura. Nesse processo, a necessidade de reorganização hospitalar ganhou legitimidade uma vez que o direito à cidadania, reivindicado no contexto da Revolução Francesa, exigia que se regularizasse a situação dos enclausurados. Surge, então, "um novo olhar sobre o hospital considerado como máquina de curar e que, se produz efeitos patológicos, deve ser corrigido" (FOUCAULT, 2011, P. 101).

As práticas de reorganização hospitalar por meio da disciplina - técnica de exercício de poder - passaram a ser confiadas ao médico, o que consequentemente contribuiu para a transformação do saber e do exercício da medicina. Para Foucault (2011), a disciplina caracterizava-se, naquela época, como uma arte de distribuição espacial dos indivíduos; uma técnica de poder que implicava uma vigilância constante e permanente, assim como um registro contínuo de informações sobre o indivíduo; "poder de individualização que tem o exame como instrumento fundamental" (FOUCAULT, 2011, P. 106-107).

Desta forma, o médico tornou-se o responsável pela organização hospitalar que, por sua vez, tornou-se um laboratório de pesquisas, espaço de exames, tratamento, ensino-aprendizagem da medicina e saber sobre as doenças. A instituição que era filantrópica passou a ter um novo caráter: $\mathrm{o}$ de hospital médico. Em decorrência destas transformações nascem os primeiros hospitais psiquiátricos cujo princípio para o tratamento dos doentes mentais passou a ser a hospitalização integral - o isolamento (FOUCAULT, 2011). A exclusão ocorre através da internação, que é o que caracteriza a institucionalização.

O contexto político e histórico de emergência da psiquiatria enquanto ciência médica foi o da sociedade disciplinar do século XVIII. Em 1809, Philip Pinel escreveu seu 'Traité Médico-Philosophique sur l'Aliénation Mentale', obra que serviria de referência para os alienistas e psiquiatras dos séculos XIX e parte do século XX. Estabeleceu as bases para um novo projeto de saber bem como as estratégias de intervenção para a psiquiatria clássica, ciência e prática médica por ele fundada. Pinel fundou as premissas do 'tratamento moral', isto é, as estratégias disciplinares desenvolvidas no interior do asilo psiquiátrico, tais como as duchas, o cárcere, o isolamento e a camisa de força, como forma de normalizar os doentes e permitir a dominação das paixões e a recuperação da razão (CAPONI, 2012).

Quando Pinel libertou os loucos, realizou a denominada primeira reforma do tratamento da loucura, utilizando o mesmo discurso moral que ainda hoje é possível observar nas várias práticas terapêuticas (CASTEL, 1991).

Só foi possível para Pinel reconhecer a existência da loucura e propor o tratamento moral, devido ao fato de que para ele "em toda loucura permanece sempre um resto de razão" (PINEL, 1809 APUD CAPONI, 2012, P. 41).

Desde a Idade Média, com a fundação dos primeiros hospitais nos monastérios, as práticas de cuidado deixaram a privacidade dos domicílios para serem exercidas também no espaço público. Os cuidados foram institucionalizados por sua vinculação a uma instituição pavimentada por relações disciplinares de hierarquização vertical. A partir do século XVIII, com a institucionalização da loucura, os cuidados passaram a exercer uma função disciplinar (FOUCAULT, 2011). 
No entanto, ressoava nessa época a questão de que a psiquiatria fosse uma medicina na qual o corpo estaria ausente, uma vez que os corpos neurológicos e anatomopatológicos lhe fogem (CAPONI, 2012). Os diagnósticos psiquiátricos buscavam, então, sustentação em três elementos: os interrogatórios, a hipnose e as drogas. Por essa razão, Foucault (2006) fala de um diagnóstico absoluto da psiquiatria em oposição ao diagnóstico diferencial da medicina clínica, de um 'corpo ampliado' como base para a constituição do saber-poder da psiquiatria com relação à loucura.

A psiquiatria se transformou em uma estratégia biopolítica que percorre o espaço social. O campo de ação dessa 'psiquiatria ampliada' refere-se, fundamentalmente, às populações. $\mathrm{O}$ conceito de degeneração, instaurado a partir do século XIX, marcadamente por influência de Morel (1857 APUD CAPONI, 2012), entre outros expoentes da teoria degeneracionista, como Cabanis e Magnan, embora transvertido por denominações modernas, afirmou-se como uma premissa da psiquiatria moderna kraepeliniana e neo-kraepeliniana.

Para Caponi (2012), a nova variedade classificatória de doenças e anomalias permitiu a proliferação de um conjunto de doenças relacionadas a comportamentos e à instituição de uma medicina do não patológico, uma vez que os degeneracionistas defendiam que a hereditariedade (herança mórbida) era o veículo de transmissão progressiva de toda forma de degeneração adquirida.

Entre as certezas da psiquiatria moderna, legitimadas pela teoria da degeneração podemos enumerar como características que ainda hoje persistem:

[...] o caráter hereditário [...], a impossibilidade de cura [...], a origem biológica e a localização cerebral dos transtornos psiquiátricos; a introdução do discurso sobre a prevenção e o risco no âmbito da saúde mental. (CAPONI,
2012, P. 175).

Embora as intervenções preventivas direcionadas ao tecido social, com o objetivo de antecipar e prevenir os desvios de comportamento e patologias cerebrais, fossem apregoadas pela psiquiatria moderna, não houve avanços em termos de novas terapêuticas substitutivas ao hospital psiquiátrico, posto que, como não se acreditava na cura das doenças mentais, o isolamento terapêutico continuava tendo sua legitimidade (CAPONI, 2012).

Some-se a isso a compreensão biologicista dos degeneracionistas sobre as doenças mentais, que as reduz à unicidade das causas orgânicas, restringindo a compreensão do sofrimento psíquico dos pacientes, desprezando seus relatos e a escuta terapêutica. Em outras palavras, tudo que diz respeito às questões subjetivas dos sofrimentos humanos foi considerado sem utilidade para a elaboração do diagnóstico e substituído pelas novas classificações nosológicas (CAPONI, 2012, P. 160). O mote passou a ser "conhecer para classificar" em detrimento do "conhecer para cuidar".

Ao longo dos séculos XIX e XX, paralelamente ao desenvolvimento das instituições no modo capitalista de produção, entre as quais, na área de saúde, o hospital tem lugar central, ocorreu a consolidação do modelo asilar como hegemônico na psiquiatria. Esse modelo caracterizou-se pela ênfase nas determinações orgânicas das doenças mentais; pela negação da existência de um sujeito; pela dissociação entre o indivíduo doente, seu sofrimento e seus contextos social e cultural, fato que resultou na anulação do sujeito como participante do tratamento eminentemente medicamentoso e dirigido ao organismo doente (AMARANTE, 2007).

Ao final da II Guerra Mundial, as condições de ausência de dignidade humana oferecidas aos pacientes psiquiátricos nos hospícios despertaram preocupações com 
relação à impotência terapêutica da psiquiatria, evidenciada pelos altos índices de cronificação das doenças mentais e de incapacitação social, o que ocasionou o surgimento de movimentos de contestação do saber e das práticas psiquiátricas no cenário mundial, na tentativa de redimensionar seu campo teórico-assistencial (AMARANTE, 2007).

A história das reformas psiquiátricas aponta para um cenário de tentativas de reformulação dos modelos adotados pela psiquiatria clássica: i) a psicoterapia institucional e as comunidades terapêuticas investiram em reformas restritas ao âmbito asilar; ii) a psiquiatria de setor e a psiquiatria preventiva representaram um nível de superação das reformas referidas ao espaço asilar; iii) a antipsiquiatria e a psiquiatria democrática italiana, por sua vez, instauraram rupturas com os movimentos anteriores, colocando em questão o próprio dispositivo médico-psiquiátrico e as instituições e os dispositivos terapêuticos a ele relacionados (AMARANTE, 2007).

Essas tentativas de reformas psiquiátricas foram fundamentais no processo de fomento à crítica ao modelo asilar e à psiquiatria. Diante deste panorama, a Reforma Psiquiátrica Brasileira teve como principal influência a experiência de Franco Basaglia e colaboradores de rompimento com o sistema asilar institucional e a psiquiatria tradicional, fato que culminou na Reforma Psiquiátrica Italiana. Nesse processo, desde a década de 1970, vêm-se discutindo as práticas centradas no modelo hospitalocêntrico e a implantação de modelos substitutivos no Brasil, sob fortes debates, buscando gradativamente promover a superação do modelo asilar, pois a saúde “não é a medrosa luta contra a 'doença' ou o 'desvio', mas produção de vida, arte de (de)subjetivação, potência do encontro" (LANCETTI, 2008, P. 11).

\section{Reflexões sobre o processo}

\section{de cuidado em saúde mental à luz dos conceitos de biopoder e biopolítica em Michel Foucault}

Os processos de desospitalização e desinstitucionalização que se desenvolveram a partir desse período produziram um deslocamento do encarregar-se das populações mediante o isolamento 'terapêutico' em instituições totais, nas quais a internação poderia perdurar por toda a vida, para uma nova noção de continuidade mediante o tratamento comunitário. Produziu-se uma relação espaço-temporal descontínua, expandindo-se a proteção da saúde mental para o espaço social, a fim de assegurar a totalidade das intervenções sobre uma pessoa, desde a prevenção até a pós-cura (CASTEL, 1987). O lócus de atuação do psiquiatra não estaria mais situado no hospício, mas na cidade, no território (BONNAFÉ 1960 APUD CASTEL, 1987).

Esse movimento deixou-nos como legado a possibilidade de ressignificação social da loucura, mas, sobretudo, nos apresentou o desafio de rever os paradigmas que até então deram base às práticas assistenciais no campo da psiquiatria. Foi a partir desse contexto que cada campo científico, seja o da saúde, seja o das ciências sociais precisou investir esforços na produção de novas formas de enfrentar as questões relativas ao sofrimento psíquico, de modo a atender às novas concepções introduzidas pelas políticas de saúde mental. Não obstante, Amarante (2007) faz pensar que, ao mesmo tempo em que se configurou a possibilidade de estabelecer um paradigma radicalmente novo, é também verdade que por muitas vezes houve transposições mecânicas que não transcenderam a essência do modelo asilar, mesmo que sob novas fisionomias.

Nessa perspectiva de contradições e disputas inscritas num contexto social e do saber em estruturação, passou a ser proposta a problematização do processo de cuidado às 
pessoas em sofrimento psíquico na rede de serviços substitutivos brasileira no sentido de avançar em busca de sua mais ampla compreensão, a partir da identificação de seus aspectos limitantes e potencializadores.

Para o alcance desse objetivo selecionamos seis artigos publicados em periódicos nacionais, que discutem a prática cotidiana da atenção psicossocial nos dispositivos prioritários da rede de atenção psicossocial brasileira. Uma vez que se trata de uma análise ancorada em referencial teórico foucaultiano, a intenção foi atender à recomendação do autor de nunca perder de vista a referência a um exemplo concreto que sirva de campo para a análise, de modo a elaborar reflexões históricas, teóricas e conceituais que permitam compreender esses exemplos referidos a nosso presente.

O estudo de Tavares et al. (2003) com a equipe multiprofissional de um Caps da cidade de Niterói, Rio de Janeiro, identificou que, entre as tecnologias de cuidar desenvolvidas no Caps, as que ocorriam com maior frequência eram "atividades que indicam que a prática de cuidar ainda é influenciada pelo modelo tradicional de atendimento" (TAVARES ET AL., 2003, P. 345). O autor conclui que, embora exista uma mudança na relação dos usuários com o serviço, fazendo-os sair de uma posição passiva para uma condição mais ativa, as atividades desenvolvidas no Caps priorizam a medicalização e o atendimento individual, em detrimento da oferta de tecnologias geradoras de maior autonomia do usuário (TAVARES ET AL., 2003).

Em outra investigação realizada no município de São Carlos, São Paulo, sobre as práticas de inclusão social dos serviços substitutivos em saúde mental, Leão e Barros (2008) identificaram algumas dificuldades desses serviços no que se refere à reabilitação psicossocial, por ainda centralizarem as ações em atendimentos clínicos e ambulatoriais e, em menor, proporção nas práticas de reinserção social. Os autores sinalizaram que embora alguns conceitos e afirmações em torno da doença mental estivessem de acordo com a proposição do novo modelo de atenção psicossocial, também foram desveladas nas frases temáticas muitas concepções representativas do modo tradicional psiquiátrico (LEÃO; BARROS, 2008).

Ambos os estudos estão em concordância com a pesquisa realizada por Martins e Amarante (2008) num Caps do município do Rio de Janeiro, que objetivou verificar a forma como se organiza o cotidiano desse serviço e as possibilidades de suas ações, tanto no seu interior quanto com relação ao território. Os autores observaram que a temática da atuação territorial era pouco presente nas discussões dos técnicos e no cotidiano do serviço. Para os autores isso seria decorrente de uma dinâmica institucional na qual as atividades encontravam-se centradas na clínica tradicional. Os profissionais não estavam envolvidos o suficiente para promover a participação da equipe nos contextos vivenciados cotidianamente pelos usuários, assim como não havia mobilização de pessoas para a articulação de redes sociais, responsabilidades e potenciais de ação (MARTINS; AMARANTE, 2008).

Desta forma, estes autores sugerem que o Caps se coloca como um serviço que convive com o manicômio e o realimenta. É justamente essa discussão política e estratégica da relação com o território que se encontra ainda pouco presente no entendimento do papel do Caps, que se posiciona como intermediário na relação com o hospital psiquiátrico, pois

da arquitetura hospitalar, que exerce seu poder de controle e de formação de corpos dóceis pela anulação das possibilidades de existência própria, ao espaço aberto do território, o tema ainda é a convivência com um poder invisível e onipresente, e a ampliação da capacidade de singularização de pessoas e de grupos. (MARTINS; AMARANTE, 2008, P. 106).

$\mathrm{Na}$ mesma direção, Yasui e Costa-Rosa (2008) fazem uma reflexão sobre os desafios 
cotidianos das instituições de saúde mental que buscam implantar o novo modelo assistencial, apesar de se depararem com práticas hegemônicas do paradigma que tentam superar. Para eles esse tipo de organização da assistência hierarquizada, não é capaz de produzir

qualquer impacto na lógica hospitalocêntrica; pelo contrário, produziram um aumento na demanda de internações ao ampliar o acesso da população às consultas psiquiátricas. (YASUI; COSTA-ROSA, 2008, P. 31).

Seguem afirmando que a divisão social do trabalho no campo da saúde gera uma hierarquização das relações, na qual o saber médico persiste em imperar sobre outros saberes, que cumprem um papel secundário, o que reproduz a divisão típica do modo capitalista de produção. A consulta do psiquiatra continua a ser tomada como a atividade prioritária e essencial, fato esse que gera uma agenda exagerada, atendimentos de curta duração visando à produtividade, medida pelo número de consultas médicas realizadas. Além disto, a consulta ou as atividades com outros profissionais da equipe reproduzem modelos tradicionais de atendimento, a exemplo do psicólogo que repete o modelo da prática liberal típica, geralmente, atendendo individualmente, o que gera uma longa lista de espera, assim como, as atividades em grupos de orientação, coordenados pela enfermeira ou pela assistente social, com conotação apenas pedagógica, o que negligencia na maior parte das vezes as demandas subjetivas específicas dos sujeitos (YASUI; COSTA-ROSA, 2008).

As práticas tradicionais dos profissionais de saúde têm se delineado em detrimento de outras formas de cuidado compatíveis com o paradigma da desinstitucionalização, tais como o estímulo à constituição de redes de cuidado ao sujeito em sofrimento psíquico no território que fortaleçam alianças de solidariedade entre os sujeitos, as famílias e a comunidade (YASUI; COSTA-ROSA, 2008).

No Caps Arthur Bispo do Rosário, localizado no Complexo Juliano Moreira na cidade do Rio de Janeiro, foi realizada uma pesquisa com os profissionais, cujo objetivo foi compreender a transição entre os modelos assistenciais por meio dos sentidos, do imaginário e das experiências de prazer e sofrimento presentes na realização do trabalho em saúde mental. Os profissionais sentem-se sobrecarregados ante o desafio de transformar as práticas em saúde mental. A falta de investimento profissional, com as restrições de recursos agrava as vivências de sofrimento, constituindo-se em mais um obstáculo para a mudança das práticas, uma vez que a precariedade das condições de trabalho permanece (VASCONCELLOS; AZEVEDO, 2010). Nesse sentido, pode-se afirmar que há ainda uma grande ineficiência nos modos de gestão dos serviços de saúde, o que denota uma dissociação entre políticas de governo e políticas públicas.

Numa abordagem apresentada por Coelho Sampaio et al. (2011) sobre o trabalho em saúde mental no contexto da reforma psiquiátrica no estado do Ceará, é possível refletir sobre as transformações ocorridas na organização dos processos de trabalho, em decorrência dos avanços referentes à implantação dos serviços substitutivos ao modelo psiquiátrico clássico e à reconfiguração do objeto de intervenção e das práticas. $\mathrm{O}$ autor chama atenção para as contradições identificadas no funcionamento dos Caps, evidenciadas por dissonâncias entre as diretrizes da política de saúde mental e a operacionalidade dos serviços, apontadas pelos trabalhadores.

Entre os diversos problemas que têm limitado a resolutividade dos Caps foram mencionados:

a ausência de uma rede de saúde mental estruturada e devidamente articulada com as demais redes assistenciais, [...] a dificuldade de contenção de crises [...]. (COElho SAMPAiO 
resultando em reinternações psiquiátricas; conflitos entre as dimensões da autonomia do sujeito, da tutela e do assistencialismo das políticas de assistência social; entre o modelo de formação e a atuação na atenção psicossocial; dificuldade na gestão do território e na gestão dos projetos terapêuticos individuais e coletivos; e terapêutica dominantemente centrada na erradicação de sintomas mediante a prescrição massificada de drogas.

A pesquisa realizada por Severo e Dimenstein (2011) em um Ambulatório de Saúde Mental (ASM) de um município nordestino, destinado a receber usuários egressos dos Caps II e sua articulação com a rede de serviços do Sistema Único de Saúde identificou que,

a grande demanda por consultas e psicotrópicos, bem como a preocupação com a desassistência em psiquiatria por parte dos técnicos e usuários quando se fala em alta, indica a predominância do modelo médico no ASM. (SEVERO; DIMENSTEIN, 2011, P. 647).

Frente a isso, sugerem que é necessária uma grande reflexão sobre o assunto, pois a partir desse contexto, de produção de novas estratégias de acolhimento e cuidado, os dispositivos precisam ser constantemente revistos (SEVERO; DIMENSTEIN, 2011).

$\mathrm{Na}$ pesquisa de Martinhago e Oliveira (2012) sobre a percepção dos profissionais com relação à sua prática nos Caps II do estado de Santa Catarina, os autores identificaram que, em situações de crise, a prática predominante adotada segue o modelo clássico da psiquiatria, centrado no controle dos sintomas, vinculado ao controle do sujeito, tendo como principais práticas a contenção, a medicação e, principalmente, a internação em hospitais. Concluem que os Caps são induzidos, de acordo com a realidade que vivenciam, a trabalharem no limiar da institucionalização, uma vez que os usuários não têm o suporte necessário para uma progressão no processo de aquisição de mais autonomia fora das instituições. (MARTINHAGO; OLIVEIRA, 2012, P. 593).

Todas essas questões confirmam o que foi referido anteriormente por Amarante (2007), segundo o qual, apesar do advento de um paradigma radicalmente novo, é possível identificar a persistência de práticas vinculadas ao modelo asilar nos serviços substitutivos em saúde mental.

Evidencia-se no campo empírico dessas pesquisas, representativo do dispositivo de saúde mental brasileiro, as formas de biopoder e biopolítica materializadas no contexto atual de nossas práticas, a saber, a medicalização dos sofrimentos cotidianos, a reprodução de práticas clínicas disciplinares remanescentes do modelo biomédico hospitalocêntrico, a compreensão do território apenas quanto à sua abrangência geográfica, a verticalidade das relações profissionais e a concepção biologicista do processo saúde-adoecimento mental.

Configura-se o que Lancetti (2008, P. 47) denominou como "Caps burocrático" visto que os profissionais procuram adaptar os usuários às especialidades, aos modelos terapêuticos já vivenciados. Os usuários é que precisam se adaptar aos serviços oferecidos, não havendo uma preocupação em buscar novas estratégias clínicas.

Tal linha de ação foi criando uma corrente tecnocrata e burocrática: os Caps envelhecem prematuramente, segmentarizam-se, sua vida torna-se cinzenta, infantilizada e os profissionais, regidos pelas dificuldades, se enclausuram em diversas formas de corporativismo. (LANCETTI, 2008, P. 47).

Quanto a essa questão, das condições de possibilidade e impossibilidade da consolidação do modo de atenção psicossocial no 
Brasil, as categorias de biopoder e biopolítica das populações, enunciadas por Foucault em 'Segurança, Território e População' (2008B), oferecem perspectivas elucidativas quanto aos processos de cuidado, tendo em vista a acepção de que as práticas de cuidado possuem um atributo relacional e, portanto, inscrevem-se num contexto de relações de poder.

Para que sejam empreendidas as análises, no âmbito deste artigo, é preciso lembrar que o poder, para Foucault, refere-se a um conjunto de mecanismos ou procedimentos

que tem como papel ou função e tema manter - mesmo que não o consigam - justamente o poder. É um conjunto de procedimentos [...], parte intrínseca de todas as relações, são circularmente o efeito e causa delas [...]. (FOUCAULT, 2008B, P. 4).

Os conceitos de biopoder e biopolítica estão vinculados a uma forma de governamentalidade que se estabeleceu nas sociedades ocidentais entre os séculos XVII e XVIII, quando se deu a transição entre o poder soberano e o biopoder, como já apresentado no início deste trabalho. Enquanto as tecnologias disciplinares estiveram essencialmente centradas nos corpos individuais, a partir da metade do século XVII, a biopolítica passou a se dirigir ao corpo-espécie, ao conjunto da população afetada pelos fenômenos da vida. As técnicas disciplinares não se extinguiram, ao contrário, passaram a compor as novas tecnologias da vida, uma vez que a biopolítica tinha como foco os fenômenos relacionados à natalidade, à morbidade e à mortalidade possibilitando a formatação de uma medicina que teria por função a higiene e a saúde públicas (FOUCAULT, 1994).

As análises de séries estatísticas tiveram papel preponderante nesse processo, pois possibilitaram cálculos, previsões, estimativas e, consequentemente, políticas direcionadas ao conjunto da população, embora necessariamente articuladas com as formas disciplinares (CAPONI, 2012).

Nesse contexto, o preventivismo representou um projeto de medicalização da ordem social, expandindo os preceitos médico-psiquiátricos para o campo das normas e dos princípios sociais; uma atualização e uma metamorfose do dispositivo de controle e disciplinamento social, estabelecendo um continuum entre a política de confinamento dos loucos e a moderna promoção da saúde mental; um novo modelo de gestão dos homens (CASTEL, 1991).

Nessa transição de um modelo de cuidados institucionalizado para um modelo comunitário de cuidados em saúde mental, outros elementos e atores passaram a operar de forma a permitir que se pudesse lograr êxito, tais como a família, a comunidade e uma rede de instituições implicadas.

Se os estudos de Michel Foucault são enunciativos de que o cuidado está implicado nesse processo como um componente das estratégias disciplinares e biopolíticas no âmbito da psiquiatria, que se dirigem às populações na profilaxia de processos degenerativos psíquicos, é preciso que questionemos o estatuto do cuidado nesse novo modelo de atenção comunitária em saúde mental.

Sobre a coexistência dos dispositivos legal, disciplinar e de segurança, Foucault (2008b) analisa que não há uma série na qual os mecanismos jurídico-legais (código legal com divisão binária entre o permitido e o proibido), os mecanismos disciplinares (mecanismos de vigilância e de correção) e os mecanismos de segurança (dispositivo que insere um fato numa série de acontecimentos prováveis) vão se suceder de forma que um mecanismo apareça e faça seus predecessores desaparecerem. "Não há a era do legal, a era do disciplinar, a era da segurança” (FOUCAULT, 2008B, P. 106-107). Há, ao contrário, um sistema de correlação entre os três mecanismos anteriormente mencionados, de forma que o corpus disciplinar é amplamente ativado e fecundado pelo estabelecimento 
de mecanismos de segurança. Por sua vez, ocorre uma verdadeira inflação do código jurídico-legal para fazer o sistema de segurança funcionar.

Os argumentos acima formulados levam-nos a questionar: quais posicionamentos pretendemos assumir sobre os processos de cuidado com o sujeito em sofrimento psíquico? O que de fato significa cuidar? Ficaremos afiliados às ideias reducionistas que limitam o campo dos sofrimentos psíquicos a causas orgânicas? Vamos restringir a compreensão dos relatos dos usuários e da escuta terapêutica a meras formalidades de uma consulta da clínica tradicional ou autorizamo-nos ao comprometimento com o cuidado integral dos sujeitos, numa clínica ampliada, considerando as causas orgânicas, mas não nos restringindo a elas?

Responder a essas questões não é tarefa fácil e para tentar encontrar algumas respostas pode ser de grande ajuda buscar subsídios na ética. O termo grego Éthos está relacionado à concepção moralizante, designando adesão às regras ou padrão de comportamento social. Refere-se ao sentido de clínica que nas práticas tradicionais em saúde tem uma conotação marcadamente assistencial, inerente ao uso médico do termo originário do adjetivo grego klinikós, segundo o qual alguém administraria seu saber para reabilitar alguém incapacitado de cuidar de si. Por sua vez, o termo $\hat{E}$ thos, empregado pela cultura helênica em seus primórdios, significa morada, abrigo, refúgio, lugar onde somos autênticos e despidos de defesas, onde estamos protegidos, abrigados, e podemos receber o outro, no sentido que os seguidores de Epicuro deram à expressão grega clinamen, entendida como a capacidade que cada homem tem para introduzir, a qualquer momento, um desvio no curso de sua vida que permita desencadear a criação de uma nova ordem (MÜLLER-GRANZOTTO; MÜLLERGRANZOTTO, 2007).

Propomos, então, a retomada da noção de cuidado, fortalecendo aquilo que para nós é fundamental: uma clínica baseada no clinamem, uma clínica que inclui o sujeito no seu processo de cuidado, de forma ampliada.

Faz-se mister significar cuidado enquanto um horizonte ético que possa proporcionar as condições necessárias para que os Caps sejam, nas palavras de Lancetti (2008), 'turbinados', mediante um conjunto de proposições filosóficas, éticas e políticas que reafirmem o compromisso das tecnociências da saúde, em seus meios e fins, com a realização de valores relacionados à felicidade humana e democraticamente validados como bem comum (AYRES, 2006).

Na percepção de Lancetti (2008, P. 50),

a ação combinada, a socialização do conhecimento e a distribuição de saberes têm a potência necessária para arrancar os Caps de sua reclusão tecnocrática e de sua tristeza burocrática,

uma vez que um Caps turbinado é um Caps paradoxal, onde a prática ocorre, ao mesmo tempo, dentro e fora das unidades de saúde, no território geográfico e no território existencial, no domicílio e nos serviços.

Nessa mesma direção, Ayres (2006) lança luz sobre essa questão do cuidado como prática de saúde, inserindo-o no movimento humano de se lançar ao mundo, numa reconstrução constante de si mesmo e desse mundo. $\mathrm{O}$ autor admite que, no campo operativo das práticas de saúde é possível considerar como cuidado uma atitude terapêutica que busque ativamente seu sentido existencial, dando ao termo cuidado a

designação de uma atenção à saúde imediatamente interessada no sentido existencial da experiência do adoecimento, físico ou mental, e, por conseguinte, também das práticas de promoção, proteção ou recuperação da saúde. (AYRES, 2006, P. 22).

Conforme discutem Schneider e colaboradores (2009), o cuidado em saúde mental no
$1 \mathrm{O}$ autor usa o termo

turbinar no sentido de dar prioridade às pessoas que estão em situação mais difícil, em maior risco de morte ou de violência, a quem está em grande dificuldade de desenvolvimento pessoal e social ou de exercício de cidadania, produzindo saúde mental de modo intenso, complexo e sempre renovado. (LANCETTI, 2008, P. 52). 
âmbito da rede de atenção psicossocial deve ser vivenciado mediante configurações em rede. Pressupõem que se estabeleçam redes de cuidado que ampliem as possibilidades de acolhimento do usuário e de seus familiares, potencializando o exercício da cidadania e da inclusão social. Tais redes devem ser compostas por entes institucionais (representados pelos serviços de saúde), ressaltando-se a importância da requalificação das equipes multiprofissionais de saúde, mas também e principalmente por entes não-institucionais (representados por associações e grupos comunitários, entre outros) situados no território do usuário, de forma a garantir a continuidade do cuidado, para além dos muros dos serviços de saúde.

\section{Considerações finais}

No cenário atual do campo da saúde mental brasileira, é preciso investir e ampliar os espaços de reflexão e de invenção de práticas que contemplem o cuidado dos sujeitos em sofrimento psíquico, no cotidiano dos serviços, potencializando a constituição da rede de atenção psicossocial. Para que esse desafio seja transposto, é preciso desnaturalizar as práticas inversamente desenvolvidas, que ampliam a medicalização dos sofrimentos cotidianos, de acordo com um modelo assistencial, cada vez mais encrudescido, conforme a tradição oriunda do

\section{Referências}

AMARANTE, P. Saúde Mental e Atenção Psicossocial. Rio de Janeiro: Fiocruz, 2007.

AYRES, J. R. C. M. O cuidado, os modos de ser (do) humano e as práticas de saúde. Saúde Soc., São Paulo, v. 13, n. 3, p. 16-29, set./dez., 2006. Disponível em: <http://www.scielo.br/scielo.php?pid=S0104$12902004000300003 \&$ script $=$ sci_arttext $>$. Acesso em: 28 maio 2013. termo originário do adjetivo grego klinikós.

Sendo assim, evidenciamos a necessidade de uma constante vigilância crítica sobre os modelos de cuidados propostos, a fim de que possa ser evitada a reprodução das práticas tradicionais do antigo modelo psiquiátrico, baseado no poder disciplinador.

No campo da saúde mental, a intersecção entre o biopoder e a biopolítica pode ser considerada como limitante ao desenvolvimento de uma clínica ampliada, que contribua para uma nova compreensão do processo saúde-sofrimento-adoecimento psíquico, bem como com a invenção de novas práticas de cuidado, consoantes às proposições da Política Nacional de Saúde Mental e de acordo com as especificidades de cada território na rede de atenção psicossocial.

A intersetorialidade apresenta-se como uma estratégia relevante para ampliar o alcance das redes de cuidado, mediante parcerias com as áreas de educação, justiça, assistência social, segurança, entre outras.

A proposta deste trabalho foi a de apresentar as categorias foucaultianas de biopoder, biopolítica e dispositivo de segurança como formas de aplicação aos estudos sobre o cuidado em saúde mental, permitindo sua eventualização, sua desnaturalização e a elucidação de sua episteme, na tentativa de favorecer novas formulações de cuidado enquanto conceito chave para as práticas de saúde no âmbito da Atenção Psicossocial.

CAPONI, S. Loucos e degenerados: uma genealogia da psiquiatria ampliada. Rio de Janeiro: Fiocruz, 2012.

CASTEL, R. A Gestão dos Riscos: da antipsiquiatria à pós-psicanálise. Rio de Janeiro: Livraria Francisco Alves Editora S. A., 1987.

A Ordem Psiquiátrica: A Idade de Ouro do Alienismo. 2. ed. Rio de Janeiro: Edições Graal, 1991. 
COELHO SAMPAIO, J. J. et al. O trabalho em serviços de saúde mental no contexto da reforma psiquiátrica: um desafio técnico, político e ético. Ciênc. saúde colet., Rio de Janeiro, v. 16, n. 12, p. 4685-4694, dez. 2011.

FOUCAULT, M. História da loucura na idade clássica. 6 ed. São Paulo: Perspectiva, 2008a.

História da Sexualidade I. A vontade de saber. Lisboa: Relógio D’ Água, 1994.

Microfísica do Poder. 29. ed. Rio de Janeiro:

Edições Graal, 2011.

O poder psiquiátrico. São Paulo: Martins Fontes, 2006.

Segurança, Território, População. São Paulo:

Martins Fontes, 2008b.

LANCETTI, A. Clínica peripatética. 3. ed. São Paulo: Hucitec, 2008.

LEÃO, A.; BARROS, S. As representações sociais dos profissionais de saúde mental acerca do modelo de atenção e as possibilidades de inclusão social. Saúde Soc., São Paulo, v. 17, n. 1, p. 95-106, mar. 2008.

MARTINHAGO, F.; OLIVEIRA, W. F. A prática profissional nos Centros de Atenção Psicossocial II (CAPS II), na perspectiva dos profissionais de saúde mental de Santa Catarina. Saúde debate, Rio de Janeiro, v. 36, n. 95 , p. 583-594, out./dez. 2012.

MARTINS, Q. R.; AMARANTE, P. A ação territorial do Centro de Atenção Psicossocial em sua natureza substitutiva. Saúde debate, Rio de Janeiro, v. 32, n.

78/79/80, p. 99-107, jan./dez. 2008.

MÜLLER-GRANZOTTO, M. J.; MÜLLER-

GRANZOTTO, R. L. Fenomenologia e Gestalt-Terapia.

São Paulo: Summus, 2007.

SEVERO, A. K.; DIMENSTEIN, M. Rede e

intersetorialidade na atenção psicossocial:

Contextualizando o papel do ambulatório de saúde

mental. Psicol., Ciênc. Prof. (Impr)., Brasília, DF, v. 31, n.

3, p. 640-655, 2011.

TAVARES, C. M. M. et al. Análise de implementação de tecnologias de cuidar em saúde mental na perspectiva da atenção psicossocial. Anna Nery Revista de Enfermagem, Rio de Janeiro, v. 7, n. 3, p. 342-350, dez. 2003.

VASCONCELLOS, V. C.; AZEVEDO, C. S. Sentidos do trabalho e imaginário organizacional em um Centro de Atenção Psicossocial - CAPS. Interface (Botucatu), Botucatu, v. 14, n. 34, p. 563-76, jul./set. 2010.

YASUI, S.; COSTA-ROSA, A. A estratégia atenção psicossocial: desafio na prática dos novos dispositivos de saúde mental. Saúde debate, Rio de Janeiro, v. 32, n. 78/79/80, p. 27-37, jan./dez. 2008.

Recebido para publicação em julho de 2015

Versão final em setembro de 2015

Conflito de interesses: inexistente

Suporte financeiro: não houve 